\title{
Role of employee training and experience on the adaption of computerized maintenance management system
}

\author{
E.A.C.P. Karunarathne
}

Department of Industrial Management, Wayamba University of Sri Lanka, Sri Lanka

A.S.M.A.R. Abeyratne

Asset Management Hydro Electrical, Ceylon Electricity Board, Sri Lanka

\begin{abstract}
The study attempted to examine the user training and experience on user acceptance of a computerized maintenance management system (CMMS) in a continuously progressing industry where maintenance management is extremely vital for the smooth functioning. A cross-sectional study design was used in this research. The study population comprised of users of CMMS. The analysis was mainly carried out using structured equation modeling techniques. The results reveal that perceived usefulness was the most significant determinant of adoption of a complex system than all the other variables, underscoring the importance of incorporating the appropriate functional capabilities in new systems. The findings affirm that a system will be adopted if it is regarded as useful, irrespective of attitude, provided that the use of the system is perceived to offer direct benefits to the user. All the relationships existing between perceived ease of use, perceived usefulness, attitude towards using, and behavioral intention were tested and found to be significant and positive. Further analysis revealed that experience helps in ease of use but not in usefulness while training impacts on both usefulness and ease of use. Based on the analysis results recommendations were made to track the value of user training and experience accordingly.
\end{abstract}

\section{Keywords}

computerized maintenance management system, employee training, experience, behavioral intention, coalbased power plants

\section{Introduction}

Due to the risen role of operational support, acceptance and use of Information Technology (IT) have received the attention of many industries for over a decade. On the other hand, with the emergence of new materials, new communication and data processing technologies, changes in industrial functions are greatly experienced by today's society (Ciutacu \& Chivu, 2015). The implementation of the Information Systems (IS) correspondingly prompts changes in attitudes and behaviours within the organization's internal structures through these IS-related acquisitions are mostly identified as strategic investments for the many firms (Amadi-Echendu \& De Wit, 2015). On the other hand, successful investment in IT can lead to productivity enhancement, while some of it leads to undesirable consequences such as financial losses and employees' dissatisfaction. Consequently, understanding the way of employees' acceptance of IS vital for those industries though their decisions are likely to vary with the system, the individual perceptions and the context. This study focuses on the coal power generating industry, where maintenance management is extremely vital for the smooth functioning of a Coal Power 
Plant (CPP) since the operations in a CPP are identified as a continuous process.

Computerized Maintenance Management Systems (CMMS) come up with comprehensive modules which enhance operational requirements of recording, analysing and reporting and increase the effectiveness and efficiency of its employees. These are used instead of the manual (paperbased) work maintenance systems that have been used for many years. The use of computers in maintenance can provide ease of access to precise data and allow users to search and find details effectively. Further, these IS offer the opportunity to manage and provide a broader scope of summarized information with greater quality than a manual system could ever provide (Wienker, Henderson, \& Volkerts, 2016; Weir, 2015).

Maintenance management systems have also been evolved with the changes in maintenance over the time. Also, these systems are equipped with advanced computational tools to manipulate a large amount of information. This meant an evolution in how to manage the maintenance both in the general concept and in each stage. Companies are using these software programs under various maintenance conditions to perform costs or expenses, to control of stock, to keep the historical record of equipment or machinery, to make planning and work order releases, and to monitor variables (Lemma, 2012; Dedrick, Gurbaxani \& Kraemer, 2003).

CMMS programs typically interface with users through customizable modules chosen based on the maintenance data requirements. Some of the most common CMMS modules perform data analysis related to preventive maintenance, parts inventory, parts procurement, work-order management, labour costs, material costs and contracting cost (Wireman, 2009). As recorded in previous studies, specialized maintenance management is not only concerned with controlling, but also with managing all tasks associated with maintenance and pays more attention to managing the asset's lifespan. It develops preventive maintenance to predictive maintenance, which strives to detect emerging faults (Lemma, 2012; Fumagalli, Macchi, \& Rapaccini, 2009).

However, employees' reluctance and low utilization of a newly adopted computerized IS and their preference to follow familiar operational methods will be caused not to make a significant contribution to the purpose of implementing a new system. This can be evidenced by the factors revealed in the Technology Acceptance Model (TAM). Thus, understanding the way those employees see the new system will be an interesting investigation.

When discussing acceptance and usage of newly implemented technologies, the most influential and accepted model which represents important theoretical contribution is TAM (Malhotra \& Galletta, 1999). Though associations of several external variables on TAM have been discussed by Davis, Bagozzi, \& Warshaw (1989), empirical research on the effect of those variables has been limited. Thus, this paper targets to provide an insight into the implication of employees' training and experience on the acceptance of CMMS after it has been implemented and to examine the postimplementation perception of employees in the coal power generating industry. Due to drastic changes in the IS developments in the recent years, understanding the employees' acceptance of such advanced technology in a complex maintenance environment would be an interesting investigation in both from an academic and an administrative perspective.

\section{Literature review}

\subsection{CMMS in Operations}

CMMS is computer software designed to simplify maintenance management operations which schedules, tracks and monitors maintenance activities to provide a range of reports and information on cost, component items, and personnel activities. Simply, it acts as a database which contains information about the company, workers, warehouse, equipment and maintenance. Thus, the data inputs play a key role in CMMS.

Most of these systems include basic modules for the identification of assets, work orders, preventive maintenance, and for keeping histories of material and equipment purchases, as well as tools for analysing information. These basic modules can provide the foundation for an effective system of maintenance administration (Cato \& Mobley, 2001; Faiz \& Edirisinghe, 2009; Labib, 2008; Lee et al., 2013; Lemma, 2012; Lopes et al., 2016; O'Donoghue \& Prendergast, 2004; O'Hanlon, 2005; Vilarinho, Lopes, \& Oliveira, 2017; Wienker et al., 2016; Zhang, Li, $\&$ Huo, 2006). These are done by organizing and tracking a lot of data which required running maintenance operations. 
In the operations perspective, maintenance costs are growing faster than production costs. Hidden costs impact of maintenance are much higher than just the direct costs associated with traditional maintenance (Wienker et al., 2016). Some studies have shown that maintenance has tended to be viewed as a "black hole" where too much money goes with little measurable return (Lopes et al., 2016; Munyensanga, Widyanto, Aziz, Rusnaldy, \& Paryanto, 2018; Wienker et al., 2016). Other than cost-effectiveness, there are many other factors to consider in determining whether a CMMS can benefit the firm operation. It also needs to consider such results as better organizational methods, reduced paperwork, and improved communications (Lemma, 2012). On the other hand, most maintenance organizations using a CMMS have been able to increase the labour productivity rates in several ways (Lemma, 2012; Lopes et al., 2016; Mather, 2002). Moreover, most computerized maintenance systems with a good preventive maintenance system will also lead to improvement of equipment or asset availability and product quality through the better planning, less firefighting, and better analysis of repair histories (Lemma, 2012; Lopes et al., 2016).

\subsection{Importance of employee training and experience in CMMS operations}

There are many reasons for the failure of CMMS. The major failures are associated with human errors, but not with the CMMS itself. A large percentage of failures occur due to the partial implementation of CMMS. Most companies lack the expertise required to implement a CMMS fully. Since their employees do not have a working knowledge of these programs or fail to understand the capabilities of the system fully, they fail to recognize all of the tasks that are required to directly or indirectly support the installed system (Amadi-Echendu \& De Wit, 2015; Lee et al., 2013; Lemma, 2012; Wienker et al., 2016). Moreover, since employees form their attitudes and perceptions on the basis of their prior experience, employees with a higher high level of experience may be highly positive towards acceptance of a newly implemented IS than others due to less susceptible (Irani, 2000).

On the other hand, training can be identified as an important human resource management practice which positively enhances the organization's performance (Pham, Phan, Tučková, Vo, \& Nguyen, 2018). Also, training has an impact on the way that the user perceives the technology implementation (Sternad \& Bobek; 2006; Alkhaldi, Yusof, \& Aziz, 2012). When implementing, a CMMS often requires several man-years of effort. However, many organizations do not have such staff with the experience and expertise to properly implement an effective CMMS (Amadi-Echendu \& De Wit, 2015; Wienker et al., 2016). Without having adequate manpower, in most cases, employees become frustrated with the slow progress being made and feel that the system is not meeting expectations. Also, expecting all employees to embrace the new CMMS system automatically can cause various issues. Proper training for workers is essential to achieve high rates of success. Without a radical change in the human factor, a CMMS system cannot provide the expected benefits (Ben-Daya, Duffuaa, \& Raouf, 2001; Lemma, 2012; Sherwin, 2000; Wienker et al., 2016).

\subsection{Adoption of computerized system: technology acceptance model (TAM)}

There have been lots of techniques on assessing learner to study the level of acceptance of users towards adoption in IT over the last twenty years (Chen, Li, \& Li, 2011; Chuttur, 2009; Dasgupta, Granger, \& McCarty, 2002, Davis, Bagozzi, \& Warshaw, 1989; Venkatesh \& Davis, 1996; Selamat \& Jaffar, 2011). TAM is the common selection among all of the theories which focus on the attitudinal explanations of individual intentions. TAM has been applied to different technologies under different situations with different control factors and different subjects, leading its proponents to believe in its robustness. Currently, researchers in the IS field consider TAM as one of the information systems fields' own theories and still put much effort into the study of research using the theory (Bagozzi, Davis, \& Warshaw, 1992; Lee, Kosar, \& Larsen, 2003).

TAM was introduced by Davis, Bagozzi, and Warshaw (1989), and is used to examine the impact of external variable towards the behavioural intention whenever people use the new system, because it explains the casual links between belief, the usefulness and ease of use of the system towards their attitude, intentions and actual usage of the system (Amadi-Echendu \& Wit, 2015; Davis et al., 1989; Malhotra \& Galletta, 1999; Musa, Othman, Zakaria, Khalid, \& Sokman, 2018).

According to Davis et al. (1989) and 
Venkatesh (1999), TAM shows acceptance of an IS by an individual is determined by two major variables namely; perceived usefulness and perceived ease of use. Together, these factors determine the attitude toward using technology. This, in turn, affects the behavioural intention to use, which then leads to actual system use.

\subsubsection{Perceived Usefulness}

User perception of ability to complete a task effectively with the support of technology is denoted by the perceived usefulness. With such perceptions, users tend to accept the new technologies to have better performance in their workplaces. This means that the user has a perception of how useful the technology is in performing his job tasks. This includes decreasing the time for doing the job, more efficiency and accuracy (Davis et al., 1989). Many studies have been noted its' importance and due recognition has been made in many theoretical models including TAM. With that remark, perceived usefulness can be defined as the degree to which a person believes that using a particular technology will enhance his or her job performance (Sumak, Hericko, Pusnik, \& Polancic, 2011; Huang \& Li, 2009; Thong et al., 2004; Venkatesh \& Davis, 2000; Davis et al., 1989). In other words, perceived usefulness refers to perceptions of a consumer regarding the outcome of an experience (Davis, Bagozzi, \& Warshaw, 1992).

\subsubsection{Perceived Ease of Use}

The user's perception of the amount of effort required to use the new system is denoted by the term perceived ease of use (Davis et al., 1989). From a technological perspective, the user belief on simplicity to use, read and understand of new technologies when enabling effortless adoption can be identified as key aspects of perceived ease of use. On the other hand, Venkatesh (2000) has reported perceived ease of use as the individual's perception of how easy the innovation is to learn and to use.

\subsubsection{Attitude toward Using}

The general favourable or unfavourable feeling of a person to work with the system and spreadsheets is referred as the attitude toward using the system (Fishbein \& Ajzen, 1975; Mokhsin, Shaffiei, Hamidi, \& Yusof, 2011; Mykytyn \& Harrison, 2003). Also, attitude involves judgment whether the behaviour is good or bad and whether the user is in favour or against performing it (Leonard,
Clonah, \& Kreie, 2004). In TAM, users' related beliefs on the consequences of a given behaviour and their evaluation of those consequences are usually explained by this factor. Further, the attitude has been identified as a partial mediator of the perceived usefulness and the intention to use variables (Davis et al., 1989). Users with favourable perception towards new technologies and related benefits of using them tend to have positive attitudes. As per the previous findings, perceived usefulness has a stronger positive direct effect on attitudes toward using, while the perceived ease of use has a small indirect effect on attitude via usefulness (Chen, Gillenson, \& Sherrell, 2002; Davis et al., 1989; Davis, 1993; Igbaria, 1993; Igbaria \& Chakrabarti, 1990; Sally, 2006; Weng, Yang, Ho, \& Su, 2018; Wua \& Wang 2005). Compared to usefulness, the total effect of ease of use on attitude exceeds the total effect of usefulness on attitude (Mokhsin et al., 2011).

\subsubsection{Behavioural intention}

The extent to which a person has realized his or her plans to perform or not to perform a specified future behaviour has denoted by the term behavioural intention (Sumak et al., 2011). If the users find the system incompatible or do not like to use the system, the system should be reshuffled or replaced with a new one. According to Lean, Zailani, Rumayah, \& Fernando, (2010), behavioural intention is a measure of the strength of one's intention to perform a specified behaviour as his or her desire. The same result is also demonstrated in Sumak et al. (2011), where the intentions of people to use the system are reflected by their understanding on how easy the system is, as one of the individual's indicators of the readiness to perform a given behaviour.

\subsubsection{Actual system use}

It is stated that attitude towards using a new information system is determined by the users' perception of usefulness and that attitude is, in turn, a key determinant of actual usage of the new information system (Davis et al., 1989). According to Fishbein and Ajzen (1975), attitude towards actual usage is determined by an expectancy of how easy the user thinks he can use the system. 


\section{Methodology}

\subsection{Research model}

This paper aims to provide an insight into the implication of employees' training and experience on the adoption of CMMS in the coal power generating industry. Due to continuous operational behaviour, maintenance management plays a vital role in the smooth functioning of the plant. Though firms have identified the strategic importance of the usage of CMMS, its effectiveness fully depends on the employees in that firm. Thus, identification of employees' acceptance of such a system would be an interesting investigation in the firms' perspective. In a lower acceptance scenario, by empowering employees through training and recruiting experience workforce are the two options available for the management to get maximum out of CMMS implementation. Hence, understanding the implication of employees' experience and training on the adoption of newly implemented IS would be an interesting investigation in both from a theoretical and a managerial perspective. Furthermore, the assessment of the above two vital factors will enable firms to rethink on implemented strategies for the smooth functioning of the plant.

The study was conducted in December 2019. This denotes that as technology proliferation continues, empirical evidence of this study may as well change. Figure 1 shows the conceptual model of this study and relationships among selected variables. This study mainly focuses on employees' behavioural intention, attitudes towards using CMMS and actual system use with reference to gained training and experience levels.

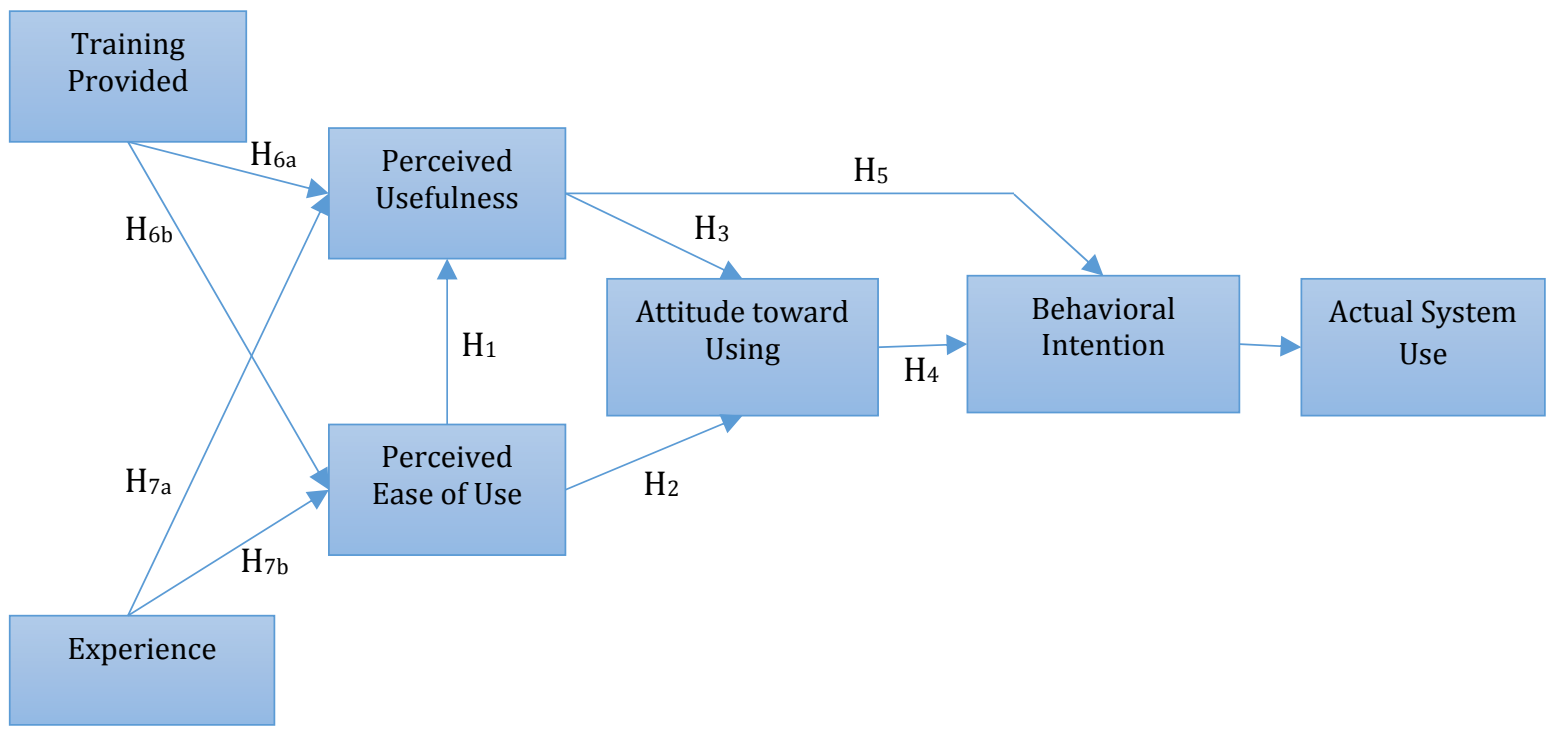

Figure 1 Model of the Study Source: The authors

\subsection{Development of hypotheses}

Concerning the above-discussed literature on customer adoption on CMMS and TAM, the following hypotheses were formulated. The study carried out considering employees' perceptions towards studying variables. Therefore throughout the study, employees' age, gender and education levels were controlled when testing the developed hypothesis in this study.

Ease of use of the CMMS is having the ability to strengthen the relationship over time. Igbaria and Chakrabarti (1990) found that ease of use is an important determinant of system usage operating through perceived usefulness. It is thought that the easier to use technology, the greater the expected benefits from the technology with regard to performance enhancements. Several studies have noted a direct effect of perceived ease of use on perceived usefulness (Davis et al., 1989; Teo, 2001). In other words, between two systems offering identical functionality, a user may find the one that is easier to use as more useful. In other words, the complexity of one particular system will become 
the inhibitor that discourages the adoption of an innovation (Rogers, 1993). On the other hand, the effective functionality of a system depends on its usability (Goodwin, 1987). With that, the following $\mathrm{H} 1$ was designed to identify changes in the relationship among ease of use and the usefulness of the CMMS.

$H_{1}$ : Perceived ease of use positively influences the usefulness of the CMMS

The existing studies suggest that perceived ease of use is a major attribute in determining the attitude of an individual towards system usage. Besides, perceived ease of use has been identified as a significant factor persuading user acceptance and usage behaviour of information technologies (Igbaria \& Livari, 1995). Users would be concerned with the effort required to use that application and the complexity of the process involved (Lee, 2010; Mokhsin et al., 2011; Ngai, Poon, \& Chan, 2007; Sumak et al., 2011). Further, according to Fishbein and Ajzen (1975), attitude towards actual usage is determined by an expectancy of how easy the user thinks he can use the system. Technology acceptance model states that perceived ease of use has a direct positive effect on attitude towards using the system. Thus, the following $\mathrm{H} 2$ was designed to identify changes in the relationship among ease of use and the attitude towards using the CMMS.

$\mathrm{H}_{2}$ : Perceived ease of use positively affects the

\section{CMMS users' attitude}

As in the past technology acceptance model studies, the first underlying relationship is that perceived ease of use and perceived usefulness will have a possible impact on enhancing user's attitude towards usage (Sumak et al., 2011; Ngai et al., 2007). It is believed that perceived usefulness was affected by the level of an individual's trust (Lee, 2010). Thus, H3 was designed to identify changes in the relationship among usefulness and the attitude towards using the CMMS.

\section{$H_{3}$ : Perceived usefulness positively influences the}

users' attitude

The attitude has been found to be a significant determinant of behavioural intention (Psouni, Hassandra, \& Theodorakis, 2016; Fishbein \& Ajzen, 1975; Liu, Liao, \& Pratt, 2009; Weng et al., 2018; Wua \& Wang, 2005). Davis (1993) has noted implications of determinants of users' attitude, has identified a strong, direct and positive effect on their intention to actually use the technology. On the other hand, a direct effect of attitude on the intention to use has also been empirically tested as a strong component for motivational variables to predict the behavioral intention of using computer technology (Taylor \& Todd, 1995). Also, a similar type of relationship was identified by Liu et al. (2009). However, this result can be negative as stated in recent research result by Sumak et al. (2011). Thus, H4 was designed to identify changes in the relationship between behavioural intention and the attitude towards using the CMMS.

$\mathrm{H}_{4}$ : Attitude towards using the CMMS positively influences the behavioural intention to use the CMMS

Perceived usefulness of an information system has been identified as the most influential factor in determining its usage. Several studies state that perceived usefulness has a significant and strong impact in determining behavioural intention to computer technology use, although perceived ease of use does not have any significant effect (Davis \& Venkatesh, 2004; Davis et al., 1989; Ma, Andersson, \& Streith, 2005; Legris, Ingham, \& Collerette, 2003). It was found that usefulness had a significantly strong relation with usage, greater than that between perceived ease of use and usage (Davis et al., 1989; Guriting \& Ndubisi, 2006; Pikkarainen, 2004). With that, H5 was designed to identify changes in the relationship among behavioural intention and the perceived usefulness in using the CMMS.

$H_{5}$ : Perceived usefulness positively influences the

behavioural intention to use the CMMS

Implications of external variables on TAM were initially discussed by Davis et al. (1989) and they noted those external variables' effects on perceived usefulness and ease of use of new technologies. By referring that development in TAM, hypothesis $\mathrm{H} 6$ and $\mathrm{H} 7$ were mainly constructed.

Many studies have revealed the importance of the employees' training when adopting newly implemented IS. Amadi-Echendu and De Wit (2015) have noted a very strong influence on how a user not only perceives and accepts a technology system and the way they utilize the technology with training. With that, implications of employee training on perceived usefulness and ease of use were examined by testing below hypotheses.

$H_{6 a}$ : Provided related training positively influences the users' perceived Ease of use of the CMMS

$H_{6 b}$ : Provided related training positively influences the perceived usefulness of the CMMS 
In a user experience perspective, many studies have also exposed the experience as a major determinant of the intention to make use of newly implemented IS. According to Horst, Kuttschreuter and Gutteling (2007), the significant direct causal influence of experience on the perceived usefulness has been identified and has noted personal experiences as one of the predictors of the perceived usefulness of eservices. Further, Irani (2000) had noted the relationship between experience and perceived usefulness and relevant prior experience was identified as the most favourable perceptions of the perceived usefulness in her study. On the other hand, employees with prior experience may identify new technologies as easy and beneficial to use and they may more positive to accept new technological implementations (Irani, 2000). Based on that, the following hypotheses were developed to measure the implications through employees' experience.

$H_{7 a}$ : Employee prior experience positively influences the perceived ease of use of the CMMS

$H_{7 b}$ : Employee prior experience positively influences the perceived usefulness of the CMMS

\subsection{Variables and measurement scales}

A multiple-item measurement scale adopted by referring to previously validated questionnaires was used to measure the identified constructs of this study. For this purpose, five-point Likertpoint scale ranging from "strongly agree" to "strongly disagree" was employed for all items.

With reference to the TAM, perceived usefulness was measured using a four-item scale which was adapted from previous studies. Operational measures used in the scale of perceived usefulness are benefits received to job performance, quick completion, easiness, and productivity (Malhotra \& Galletta, 1999). For the purpose of measuring Perceived Ease of Use, a four-item scale was utilized mainly referring to Selamat and Jaffar (2011). Individuals were asked to indicate the extent of agreement and operational measures used in the scale of perceived ease of use are easiness to learn, easiness to use, flexibility, clarity and comprehensibility. Attitude to using CMMS was also measured using a four-item scale which was adopted from Weng et al. (2018). Operational measures used in the scale of attitude towards using are goodness, positive influence of using, valuableness and trend to use. For the development of behavioural intention measurement scale past studies of Malhotra and Galletta (1999) was referred. Four-item scale was developed for this purpose and operational measures used in the scale are using for communication, frequency of using, using to do the job and using to plan meetings. Three-item scale was used to measure the actual system usage. It is measured in terms of frequency of system use ('how often') and the volume of system use ('how much') by the user (Malhotra $\&$ Galletta, 1999). The employee experience and training gained were measured placing direct questions related to both constructs. Further, before proceeding with the analysis, several statistical tests were followed to verify the reliability and validity of selected scales.

\subsection{Data collection}

For this study, the primary data was collected by steering a survey using offline questionnaires and the data collection process lasted for three weeks. A self-administered questionnaire was used to collect data which contained instrument scales to measure the study variables. The designed English language questionnaire was professionally translated into the local language (Sinhala) to make it easy for respondents to understand the measurements. Users of the CMMS in the CPP were the target group for this study and participants were selected randomly. A total of 200 structured off-line questionnaires were distributed with a letter requesting their participation in the study. The respondents had been given sufficient time to fill up the questionnaire. By excluding those with omissions or with randomly repeated answers, 164 valid responses were identified and considered for the analysis. The secondary data was used from various reports, internet sources, literature review and documents written on the subject. This was used to compare and contrast the study variables. Validity and reliability analyses were performed using Statistical Package for the Social Sciences (SPSS) and Analysis of Moment Structures (AMOS), and the research hypotheses were tested using structured equation modelling.

\section{Analysis of data}

\subsection{Sample Profile}

Many statistical techniques were used for the data analysis purpose. The initial part of the 
questionnaire contained several sociodemographic questions to get a basic idea on the sample profile. For this purpose, descriptive statistics were basically used. According to the descriptive, the sample consists of $62.2 \%$ executives and 37.8\% non-executives. Among these, $89 \%$ were males while the rest were females. Further, in the context of age category, $34.1 \%$ of the sample comprises the over-40-yearold employees. On the other hand, $46.3 \%$ have received training on CMMS while 50\% respondents of the sample have experience with CMMS usage.

\subsection{Measuring validity and reliability of study variables}

As an initial step, a series of exploratory factor analysis was followed for all the constructs which measured by using more-than-one-item scale to examine the internal consistency of the sample since the constructs were adopted by referring several past studies in different industries. By employing Maximum Likelihood factoring estimation, four dimensions of TAM were identified in line with the design. Promax rotation was applied as the orthogonal rotation method in factoring estimation. To verify sampling adequacy, Kaiser-Meyer-Olkin (KMO) result was obtained and the test result indicates commendable sample adequacy $(0.913)$ to carry out the study. Further, the model explained $69.34 \%$ of the total variance.

Then, to measure the reliability of each categorized factor, Cronbach's Alpha test followed and a sound reliability level was identified by getting over 0.7 values for all examined factors (Perceived usefulness $=0.926$, Ease of use $=0.884$, Attitude $=0.885$, Behavioral intention $=0.872$ ).

\subsection{Validating measurement model}

For this purpose, confirmatory factor analysis (CFA) was performed with the measurement model. CFA is a useful way to approach construct validation (Bagozzi \& Foxall, 1996) and through the analysis, satisfying validity evaluation standards were identified for the construct fitness (Chi-Square $=347.24 ;$ df $=147 ; \mathrm{P}=.000 ; \mathrm{CMIN} / \mathrm{DF}=$ 2.362; $\mathrm{GFI}=.839 ; \mathrm{AGFI}=.770 ; \mathrm{NFI}=.861 ; \mathrm{CFI}=.914$; RMSEA $=.091)$.

\subsection{Structural model}

By following Structural Equation Modelling technique, the statistical significance of the proposed relationships concerning employees' training and experience level was assessed. Path diagram of the empirical casual model is shown below in Figure 1.

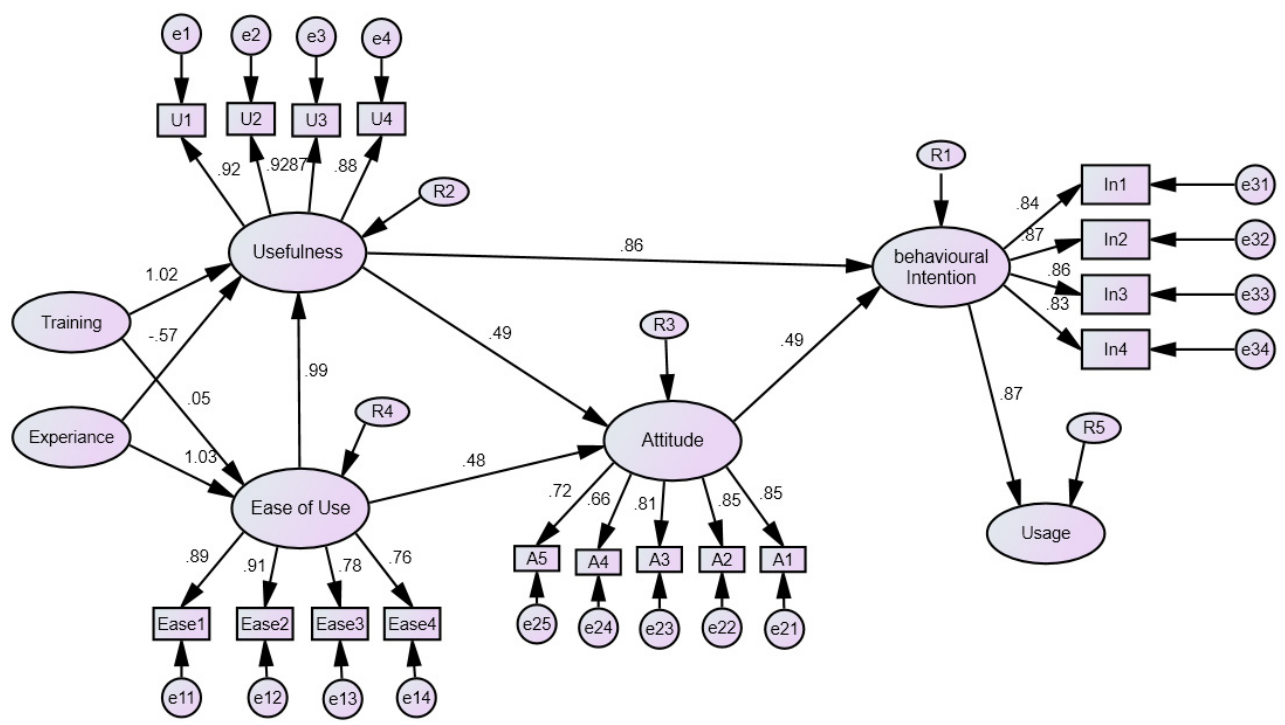

Figure 2 The output of the empirical causal model (SEM) Source: Authors' own research findings 
Common model fit criteria were used to measure the acceptance of the Structural model. As per analysis results, acceptable level of model fit measures was achieved (Chi-square $=472.071$; $\mathrm{p}=.000 ; \mathrm{CMIN} / \mathrm{DF}=2.950, \mathrm{GFI}=0.816 ; \mathrm{AGFI}$ $=0.759 ; \mathrm{RMR}=0.48 ; \mathrm{NFI}=0.812 ; \mathrm{CFI}=0.865$; RMSEA $=0.109$ ).

\subsection{Hypothesis testing}

The hypothesized relationships were investigated by the following path analysis technique in AMOS.

H1: Perceived ease of use positively influences the usefulness of the CMMS

Following the parameter estimates, results of the path analysis show that ease of use was positively and significantly related to usefulness ( $p>0.01$ ). In other words, according to the test results, the regression weight for ease of use in the prediction of usefulness is significantly different from zero at the 0.001 level (two-tailed). Thus, the null hypothesis of no positive relationship between ease of use and usefulness was rejected as the significant level is less than 0.05 . Furthermore, the model shows a higher level of explanatory power with ease of use and perceived usefulness having squared multiple correlation (SMC) value of 0.99. It implies that when perceived ease of use goes up by 1 standard deviation, perceived usefulness goes up by almost equal level.

H2: Perceived ease of use positively affects the CMMS users' attitude

Results of the path analysis show that perceived ease of use was positively and significantly related to attitude $(\mathrm{p}>0.01)$. Thus, the null hypothesis of no positive relationship between ease of use and attitude was rejected as the significant level is less than 0.05 . Furthermore, the model shows a moderate level of explanatory power having squared multiple correlation (SMC) value of 0.48 .

H3: Perceived usefulness positively influences the users' attitude

Test results indicate that perceived usefulness was positively and significantly related to attitude ( $p>0.01$ ). According to the test results, the regression weight for usefulness in the prediction of attitude is significantly different (0.49) from zero at the 0.001 level (two-tailed). Thus, the null hypothesis of no positive relationship between perceived usefulness and attitude was rejected as the significant level is less than 0.05 .
H4: Attitude towards using the CMMS positively influences the behavioural intention to use the CMMS

According to with the parameter estimates, results indicate a significant difference with a moderate level of explanatory power $(\mathrm{SMC}=0.49)$. Therefore, the null hypothesis of no positive relationship between behavioural intention and attitude was rejected as the significant level is less than 0.05 .

H5: Perceived usefulness positively influences the

behavioural intention to use the CMMS

According to the parameter estimates, results of the path analysis show that perceived usefulness was positively and significantly related to behavioural intention $(p>0.01)$. Therefore, the null hypothesis of no positive relationship between usefulness and the behavioral intention was rejected as the significant level is less than 0.05 . Further, a higher level of explanatory power with perceived usefulness and the behavioral intention was identified with the squared multiple correlation (SMC) value of 0.86 .

H6a: Provided related training positively

influences the users' perceived ease of use of the CMMS

Findings from the study revealed a significant positive correlation between perceived ease of use and provided training on the system $(\mathrm{SMC}=$ 0.83). Therefore, the null hypothesis of no positive relationship between ease of use and employee training was rejected. This implies that training provided to the employees influences the perceived usefulness of the system significantly.

H6b: Provided related training positively influences the perceived usefulness of the CMMS

According to the findings of study training provided to the employees has a significant positive effect on perceived ease of use $(p>0.01)$. Thus, the null hypothesis was rejected. The model shows a higher level of explanatory power with perceived usefulness and training provided (SMC =1.02).

H7a: Employee prior experience positively influences the perceived Ease of use of the CMMS

A positive significant effect on perceived ease of use and employees' experience was identified through the analysis $(\mathrm{p}>0.01)$. Therefore, the null hypothesis of no positive relationship between ease of use and employee experience was rejected as the significant level is less than 0.05 . The model shows a higher level of explanatory 
power with ease of use and employee experience by giving SMC value of 1.03 .

H7b: Employee prior experience positively influences the perceived usefulness of the CMMS

The results of the study show a negative correlation between perceived usefulness and employees' experiences with CMMS (SMC = 0.57). Therefore, not enough evidence was found in this study to reject the null hypothesis at the $95 \%$ confidence level.

\section{Discussion}

In this study, the main objective was to analyze and examine the role of employees' training and their experience on the adoption of the maintenance management system and thereby to assess the actual usage of CMMS in the industry where continuous process going on.

The findings of the study revealed that there was a significant positive relationship between perceived ease of use and perceived usefulness which implies that the more users perceive CMMS to be easy to use, the more they will see it as useful. This finding is consistent with previous scholarly studies which revealed that firms which have a strong and favourable perception of the usefulness of the systems, use more than those with a weak or unfavourable perception of the usefulness of the systems (Venkatesh, 2000; Teo, 2001; Davis et al., 1989).

Furthermore, there was a significant positive correlation between perceived ease of use and attitudes towards using the CMMS. This implies that the perceived ease of use by the employees influences to change their attitudes towards using the system significantly. In other words, users intend to use the system more frequently as the system becomes easy to use. Thus, by making the system more friendly, system usage can be increased with employees' attitudinal change which ultimately impacts their job performance. Moreover, the findings of the study revealed that there was a significant positive correlation between perceived usefulness and attitudes towards using CMMS. This meant that users are likely to form a positive attitude toward using the system when it is proven as a useful utility to the practice.

The result for the relationship between attitude and behavioural intention to use contradicts with the previous study of Sumak et al. (2011), where there was no stronger relationship between them. According to the present study result, there was a significant positive correlation between attitude towards using the system and behavioural intention. This implies that if employees have a positive attitude towards using the CMMS, then they intend to use it. This has further verified the findings of Psouni et al. (2016); Fishbein and Ajzen, (1975); Liu et al, (2009); Weng et al, (2018); Wua and Wang (2005).

One of the biggest obstacles to an effective CMMS installation is the lack of initial training on the system. Many organizations never take the time upfront to properly train their people on the system. People must gain confidence in using the system for reporting work order information and knowing how to look up parts information. However, analysis results indicate that there is a positive effect of gained training in perceived usefulness and ease of use.

The CMMS implementation plan should include an adequate level of actual hands-on experience on the system for all maintenance employees prior to the "go live" date. According to analysis results, there is a larger impact of experience on ease of use while a negative impact on usefulness. It gives an indication that previous experiences in using maintenance systems make them to use it easily. But with that experience, employees do not recognize the usefulness of the particular investment.

\section{Conclusions and implications}

The study examined the relationship between perceived ease of use, perceived usefulness, attitude towards using, behavioural intention, user experience, provided training and actual usage of CMMS. Through the analysis, except the implications of experience on usefulness, all the other relationships were found to be significant and positive.

Many designers believe that the key barrier to user acceptance is the lack of user-friendliness of the systems and adding user interfaces that increase usability is the key to overcome such barriers. However, this study results indicate that although the ease of use is clearly important, the usefulness of a system is even more important, and should not be overlooked. Users may be willing to tolerate a difficult interface in order to access functionality that helps them on their job, while no amount of ease of use can compensate for a system that does not do a useful task. As a result, from the user's perspective, the ease of use may be identified as part of the cost of using the system when the system does not provide 
productive performance. On the other hand, users may recognize the productive performances of the system as benefits through the usefulness construct.

On the other hand, through this study, the importance of employee training and experience were identified to enhance their perceptions towards perceived ease of use and usefulness. User training has greatly affected the perceived usefulness though they didn't get much familiar with such a complex IS. Nevertheless, the employees' previous experience with such systems has enabled them to get familiar with the newly implemented system which ultimately enables them to understand the usefulness. Moreover, though the several respondents had experience with IS, not all of them were perfectly comfortable with the CMMS which affect their perceptions. Less experienced and less trained users find the technology difficult to use and less enjoyable, which might have led to a negative attitude.

The conclusion can therefore be made that factors that motivate individual users in different societies to accept technology should be conducted prior to introducing the complex IS. User training and their experience with working such complex modules will greatly affect the usage of the system which ultimately affects the whole organization's performance. These studies could enable organizations to determine the factors that are likely to lead to high outcomes in a complex industrial scenario rather than simply copying what has worked elsewhere; due to the differences in settings and perceptions.

\section{Recommendations}

The findings of the study posit that perceived usefulness and ease of use were found to be more important in influencing CMMS acceptance. Therefore the designers need to focus on enhancing its' usefulness and familiarity. Usefulness can be simply enhanced by including missing functionalities, and at the same time, designers can focus more on replacing complex procedures into simple functions to make things easy for the user to adopt.

The findings of this study also revealed the importance of the user training and experience on their acceptance. Training should be focused not only on educating about related benefits but also on enhancing its familiarity due to system complexity in these types of industries. Thus, due to systems' complexity, staff training, the financial benefits of a new system, system simplified manuals, trial usage, persuasion for usefulness, etc. can be incorporated to motivate individual users in different societies to accept technology.

Fostering a higher level of commitment of end-users by educating them about the need and relevance of the chosen information system for individual and organizational performance is also required. Moreover, training given to employees and prior experience of using IS improve the usefulness and ease of use respectively. There should be a fit between the task, job and technology since the technology is accepted and utilized because of its usefulness to the job or task being performed.sm

\section{References}

Alkhaldi, A.N., Yusof, Z.M., \& Aziz, M.J. (2012). Impact of user training and support on video-conferencing usage in organizations in Jordan using structural equation modelling analysis approach. World Appl. Sci. J., 19(11), 1553-1562.

Amadi-Echendu, J.E., \& De Wit, F.C.P. (2015). Technology adoption: A study on post-implementation perceptions and acceptance of computerized maintenance management systems. Technology in Society, 43, 209218.

https://doi.org/10.1016/j.techsoc.2015.09.001

Bagozzi, R.P., Davis, F.D., \& Warshaw, P.R. (1992). Development and test of a theory of technological learning and usage. Human Relat., 45(7), 659-686. https://doi.org/10.1177/001872679204500702

Bagozzi \& Foxall (1996). Construct validation of a measure of adaptive-innovative cognitive styles in consumption. International Journal of Research in Marketing, 13, 201213. https://doi.org/10.1016/0167-8116(96)00010-9

Ben-Daya, M., Duffuaa, S.O., \& Raouf, A. (2001). Maintenance Modelling and Optimization. Kluwer Academic Publishers, London.

Cato, W.W., \& Mobley, R.K. (2001). Computer-managed maintenance systems: a step-by-step guide to effective management of maintenance, labor, and inventory. Butterworth-Heinemann.

Chen, L., Gillenson, M., \& Sherrell, D. (2002). Enticing online consumers: An extended technology acceptance perspective. Information and Management, 39, 706719. https://doi.org/10.1016/S0378-7206(01)00127-6

Chen, S.C., Li, S.H., \& Li, C.Y. (2011). Recent related research in technology acceptance model: a literature review. Australian Journal of Business and Management Research, 1(9), 124-127. Retrieved May 25, 2020, from http://ajbmr.com/articlepdf/AJBMR_19_04i1n9a14.pdf

Chuttur, M. (2009). Overview of the Technology Acceptance Model: Origins, Developments and Future Directions. Sprouts: Working Papers on Information Systems, 9(37). http://sprouts.aisnet.org/9-37 
Ciutacu, C., \& Chivu, L. (2015). Romania's Deindustrialisation. From the "Golden Age" to the "Iron Scrap Age". Procedia Economics and Finance, 22, 209215. https://doi.org/10.1016/S2212-5671(15)00264-6

Dasgupta, S., Granger, M., \& Mcgarry, N. (2002). User acceptance of e-collaboration technology: an extension of the technology acceptance model. Group Decision and Negotiation, 11, 87-100. https://doi.org/10.1023/ A:1015221710638

Davis, F. D. (1993). User acceptance of information technology: System characteristics, user perceptions and behavioral impacts. International Journal of ManMachine Studies, 38, 475-487. https://doi.org/10.1006/ imms.1993.1022

Davis, F.D., \& Venkatesh, V. (2004). Toward Preprototype User Acceptance Testing of New Information Systems: Implications for Software Project Management. IEEE transactions on engineering management, 51(1), 31-46. https://doi.org/10.1109/TEM.2003.822468

Davis, F., Bagozzi, R., \& Warshaw, P. (1992). Extrinsic and intrinsic motivation to use computers in the workplace. Journal of Applied Social Psychology. 22, 1111-1132. https://doi.org/10.1111/j.1559-1816.1992.tb00945.x

Davis, F.D, Bagozzi, R.P., \& Warshaw, P. R. (1989). User acceptance of computer technology: A comparison of two theoretical models. Management Science, 35, 982 $-1003$.

https://doi.org/10.1287/mnsc.35.8.982

Dedrick, J., Gurbaxani, V., \& Kraemer, K.L. (2003). Information Technology and Economic Performance: A Critical Review of the Empirical Evidence. ACM Computing Surveys, 3(1), 1-29. https://doi.org/10.1145/641865.641866

Faiz, R.B. \& Edirisinghe, E.A., (2009). Decision Making for Predictive Maintenance in Asset Information Management. Interdisciplinary Journal of Information, Knowledge and Management, 4, 23-36. https://doi.org/ 10.28945/696

Fishbein, M.. \& Ajzen, I. (1975). Belief, attitude, intention and behavior: An introduction to theory and research. Reading, MA: Addison-Wesley.

Fumagalli, L., Macchi, M., \& Rapaccini, M. (2009). Computerized Maintenance Management Systems in SMEs: a survey in Italy and some remarks for the implementation of Condition Based Maintenance. Information Control Problems in Manufacturing: IFAC Proceedings, 42(4), 1615-1619. https://doi.org/10.3182/ 20090603-3-RU-2001.0416

Goodwin, N. C. (1987). Functionality and usability. Communications of the ACM. 30(3), 229-233. https:// doi.org/10.1145/214748.214758

Guriting, P., \& Ndubisi, N.O. (2006). Borneo online banking evaluating customer perception and behavioral intention. Management Research News, 29(2), 6-15. https://doi.org/10.1108/01409170610645402

Horst, M., Kuttschreuter, M., \& Gutteling, J.M. (2007). Perceived usefulness, personal experiences, risk perception and trust as determinants of adoption of egovernment services in The Netherlands. Computers in Human Behavior, 23, 1838-1852, https://doi.org/ 10.1016/j.chb. 2005.11.003

Huang, J., \& Li, Y. (2009). The mediating effect of knowledge management on social interaction and innovation performance. International Journal of Manpower. 30(3), 285-301. https://doi.org/10.1108/01437720910956772
Irani, T. (2000). Prior Experience, Perceived Usefulness and the Web: Factors Influencing Agricultural Audiences' Adoption of Internet Communication Tools. Journal of Applied Communications, 84(2), https://doi.org/10.4148/1051-0834.2151

Igbaria, M. (1993). User Acceptance of Microcomputer Technology: An Empirical Test. Omega International Journal of Management Science, 21(1), 73- 90. https:// doi.org/10.1016/0305-0483(93)90040-R

Igbaria, M., \& Chakrabarti, A.(1990). Computer anxiety and attitudes towards microcomputer use. Behavior and Information Technology. 9, 229-241. https://doi.org/ 10.1080/01449299008924239

Igbaria, M., \& Livari, J. (1995). The effects of self-efficacy on computer usage. Omega, 23(6), 587-605. https://doi.org/10.1016/0305-0483(95)00035-6

Labib, A. (2008). Computerized maintenance management systems. In: Complex systems maintenance handbook. Springer Series in Reliability Engineering, Springer, Berlin, 417-436. https://doi.org/10.1007/978-1-84800-011-7 17

Lean, O.K., Zailani, S., Rumayah, T., \& Fernando, Y. (2010). Factors Influencing Intention to Use eGovernment Services Among Citizens in Malaysia. Computers \& Educations, 334-336. https://doi.org/ 10.4018/978-1-61520-931-6.ch019

Lee, M. (2010). Explaining and Predicting User's Continuance Intention Toward e-Learning: An Extension of the Expectation-Confirmation Model. Computers \& Educations, 54, 506-516. https://doi.org/10.1016/ i.compedu.2009.09.002

Lee, J., Lee, M.S., Lee, S.H., Oh, S.G., Kim, B.H., Nam, S.H., \& Jang, J.S. (2013). Development of Computerized Facility Maintenance Management System Based on Reliability Centered Maintenance and Automated Data Gathering. International Journal of Control and Automation, 6. Retrieved May 25, 2020, from http://sersc.org/journals/index.php/IJCA/article/view/143

Lee, Y., Kosar, K., \& Larsen, K.R.T. (2003). The Technology Acceptance Model: Past, Present, and Future. Communications of the Association for Information Systems, 12, 752-780. https://doi.org/ 10.17705/1CAIS.01250

Legris, P., Ingham, J., \& Collerette, P. (2003). Why do people use information technology? A critical review of the technology acceptance model. Information Management, 40(3), 191-204. https://doi.org/10.1016/ S0378-7206(01)00143-4

Lemma, T.A. (2012). Intelligent fault detection and diagnosis system for a cogeneration and cooling plant. PhD thesis, Universiti Teknologi Petronas Retrieved May 25, 2020, from http://utpedia.utp.edu.my/id/eprint/3326

Leonard, L.N.K., Clonah, T.P., \& Kreie, J. (2004). What influences information technology, ethical behavioral intention, planned behavior, reasoned action, perceived importance, or individual Characteristics? Information and Management, 42,143-158. https://doi.org/10.1016/ j.im.2003.12.008

Liu, S., Liao, H., \& Pratt, J. A. (2009). Impact of Media Richness and Flow on e-Learning Technology Acceptance. Computers \& Education, 52(3), 599-607. https://doi.org/10.1016/j.compedu.2008.11.002 
Lopes, I., Senra, P., Vilarinhoa, S., Sáa, V., Teixeiraa, C., Lopes, J., Alvesa, A., Oliveiraa, J.A., \& Figueiredoa, M. (2016). Requirements specification of a computerized maintenance management system - a case study. Procedia CIRP, 52, 268-273. https://doi.org/10.1016/ j.procir.2016.07.047

Ma, W.K., Andersson, R., \& Streith, K.O. (2005). Examining user acceptance of computer technology: An empirical study of student teachers. Journal of computer assisted learning, 21(6), 387-395. https://doi.org/10.1111/j.1365-2729.2005.00145.x

Malhotra, Y. \& Galletta, D.F. (1999). Extending the Technology Acceptance Model to Account for Social Influence: Theoretical Bases and Empirical Validation. Proceedings of the 32nd Hawaii International Conference on System Sciences. https://doi.org/ 10.1109/HICSS.1999.772658

Mather, D. (2002). CMMS: A Timesaving Implementation Process. CRC PRESS, New York.

Mokhsin, M., Shaffiei, Z.A., Hamidi, S., \& Yusof, N.M. (2011). Measurement of User's Acceptance and Perceptions towards Campus Management System (CMS) Using Technology Acceptance Model (TAM). International Journal of Information Processing and Management, 2(4), 34-46. https://doi.org/10.4156/ ijipm.vol2.issue4.4

Munyensanga, P., Widyanto, S.A., Aziz, M.N.A., Rusnaldy, \& Paryanto (2018). Information management to improve the effectiveness of preventive maintenance activities with computerized maintenance system at the intake system of circulating water pump. Procedia CIRP, 78, 289-294.

https://doi.org/10.1016/j.procir.2018.09.044

Musa, M.H.B., Othman, A.K.B., Zakaria, W.B., Khalid, R.B.M., \& Sokman, Y.B. (2018). The acceptance of eTPP reporting system by using TAM model. Journal of Academia UiTM Negeri Sembilan, 6(1), 8-20. Retrieved May 25, 2020, from https://nsembilan.uitm.edu.my/joacns/images/ v6_n1/pdf/MohdHafizan_6_1_A2.pdf

Mykytyn, P. \& Harrison, D.A. (2003). The application of the TRA to strategic management and strategic information systems. Information Resources Management Journal, 6(2). https://doi.org/10.4018/irmj.1993040102

Ngai, E., Poon, J., \& Chan, Y. (2007). Empirical Examination of the Adoption of Web CT using TAM. Computers \& Educations, 48, 599-607. https://doi.org/ 10.1016/j.compedu.2004.11.007

O'Donoghue, C.D. \& Prendergast, J.G. (2004). Implementation and benefits of introducing a computerized maintenance management system into a textile manufacturing company. Journal of Mater Process Technology, 153-154, 226-32. https://doi.org/ 10.1016/j.jmatprotec.2004.04.022

O'Hanlon, T. (2005). Computerized Maintenance Management and Enterprise Asset Management Best Practices. Retrieved May 25, 2020, from : http://www.cmmscity.com

Pham, N.T., Phan, Q.P.T., Tučková, Z., Vo, N., \& Nguyen, L.H.L. (2018). Enhancing the organizational citizenship behavior for the environment: the roles of green training and organizational culture, Management \& Marketing. Challenges for the Knowledge Society, 13(4), 11741189. https://doi.org/10.2478/mmcks-2018-0030.
Pikkarainen, T. (2004). Customer acceptance of online banking: An extension of the Technology Acceptance Model. Internet Research, 16(2). https://doi.org/ 10.1108/10662240410542652

Psouni, S., Hassandra, M., \& Theodorakis, Y. (2016). Exercise and healthy eating intentions and behaviors among normal weight and overweight /obese adults. Psychology, 7(4). https://doi.org/10.4236/psych.2016. 74062

Rogers, M. (1993). Diffusion of Innovation (14 $4^{\text {th }}$ ed.). the Free Press, New York.

Sally, M. (2006). Applying the technology acceptance model to the online retailing of financial services, Nottingham University Business School, Nottingham, UK. International Journal of Retail \& Distribution Management, 34 (4/5), 388-410. https://doi.org/ 10.1108/09590550610660297

Selamat, Z., \& Jaffar, N. (2011). Information Technology Acceptance: From Perspective of Malaysian Bankers. International Journal of Business and Management, 6(1), 207-217. https://doi.org/10.5539/iibm.v6n1p207

Sherwin, D. (2000). A review of overall models for maintenance management. Journal of Quality in Maintenance Engineering, 6, 138-164. https://doi.org/ 10.1108/13552510010341171

Sumak, B., Hericko, M., Pusnik, M., \& Polancic, G. (2011). Factors Affecting Acceptance and Use of Moodle: An Empirical Study Based on TAM. Faculty of Electrical Engineering and Computer Sciences, University of Maribor. Informatica, 35, 91-100. Retrieved May 25, 2020, from http://www.informatica.si/index.php/informatica/article/d ownload/336/335

Sternad, S. \& Bobek, S. (2006). Factors which have fatal influence on ERP implementation on Slovenian organizations. Journal of Information and Organizational Science, 30(2), 279-293. Retrieved May 25, 2020, from https://jios.foi.hr/index.php/jios/article/view/23

Taylor, S., \& Todd, P.A. (1995). Understanding Information Technology Usage: A Test of Competing Models. Information Systems Research, 6,144-176. https:// doi.org/10.1287/isre.6.2.144

Teo, T.S.H. (2001). Demographic and motivation variables associated with Internet usage activities. Internet Research, 11(2), 125-137. https://doi.org/10.1108/ 10662240110695089

Thong, J.Y.L, Hong, W., \& Tam, K.Y. (2004). What leads to user acceptance of digital libraries? Common. ACM, 47(11), 79-83. https://doi.org/10.1145/ 1029496.1029498

Venkatesh, V. (1999). Creation of favorable user perceptions: exploring the role of intrinsic motivation. MIS Q, 23(2), 239-260. https://doi.org/10.2307/249753

Venkatesh, V. (2000). Determinants of perceived ease of use: Integrating control, intrinsic motivation, and emotion into the Technology Acceptance Model. Information Systems Research, 44(4), 342. https:// doi.org/10.1287/isre.11.4.342.11872

Venkatesh, V. \& Davis, F.D. (1996). A model of the antecedents of perceived ease of use: Development and test. Decision Sciences, 27(3), 451-481. https:// doi.org/10.1111/j.1540-5915.1996.tb01822.x 
Venkatesh, V. \& Davis, F.D. (2000). A theoretical extension of the technology acceptance model: Four longitudinal field studies. Management Science, 46(2), 186-204. https://doi.org/10.1287/mnsc.46.2.186.11926

Vilarinho, S., Lopes, I., \& Oliveira, J.A. (2017). Preventive maintenance decisions through maintenance optimization models: a case study. Procedia Manufacturing, 11, 1170-1177. https://doi.org/10.1016/ j.promfg.2017.07.241

Weir, B. (2015). Computerised Maintenance Management Systems (CMMS): An Impartial View of CMMS Functions, Selection and Implementation. Plant Maintenance Resource Center. Retrieved May 25, 2020, from

https://www.plantmaintenance.com/articles/CMMS syst ems.shtml

Weng, F., Yang, R.J., Ho, H.J., \& Su, H.M. (2018). A TAMBased Study of the Attitude towards Use Intention of Multimedia among School Teachers. Applied System Innovation, 1(36).

https://doi.org/10.3390/asi1030036

\section{$\triangle$ Correspondence}

\section{E.A.C.P. Karunarathne}

Department of Industrial Management, Faculty of Applied Sciences,

Wayamba University of Sri Lanka,

Lional Jayathilaka Mawatha,Kuliyapitiya-60200, Sri Lanka

E-mail: chami@wyb.ac.lk
Wienker, M., Henderson, K., \& Volkerts, J. (2016). The Computerized Maintenance Management System - An essential Tool for World Class Maintenance. Procedia Engineering, 138, 413-20. https://doi.org/10.1016/ j.proeng.2016.02.100

Wireman, T. (2009). Developing Performance Indicators for Managing Maintenance ( $2^{\text {nd }}$ ed. $)$. John Carleo. New York: Industrial Press.

Wua, J.H., \& Wang, S.C. (2005). What drives mobile commerce? An empirical evaluation of the revised technology acceptance model. Information \& Management, 42, 719-729. https://doi.org/10.1016/ j.im.2004.07.001

Zhang, Z., Li, Z., \& Huo, Z. (2006). CMMS and its application in power system. International Journal of Power Energy System, 26, 75-82. https://doi.org/ 10.2316/Journal.203.2006.1.203-3441 